\title{
EXTRATOS DE ESPÉCIES DE CAPSICUM NO CONTROLE IN VITRO DE PATÓGENOS DE IMPORTÂNCIA AGRÍCOLA
}

José Roberto Vieira Júnior ${ }^{1}$, Cléberson de Freitas Fernandes ${ }^{1}$, Simone Carvalho Sangi $^{2}$, Tamiris Chaves Freire ${ }^{3}$, Aline Souza da Fonseca ${ }^{3}$.

${ }^{1}$ Pesquisador, Doutor da Embrapa Rondônia

${ }^{2}$ Mestranda em Ciências Ambientais

${ }^{3}$ Doutoranda em Biodiversidade e Biotecnologia, Universidade Federal de Rondônia Autor para correspondência: jose-roberto.vieira@embrapa.br, Empresa Brasileira de

Pesquisa Agropecuária. Porto Velho - Brasil

Recebido em: 08/04/2017 - Aprovado em: 10/06/2017 - Publicado em: 20/06/2017 DOI: 10.18677/EnciBio 2017A52

\begin{abstract}
RESUMO
Nos últimos 30 anos tem-se observado, por parte da sociedade, uma maior preocupação com o uso de agrotóxicos na agricultura. Nesse sentido, a pesquisa tem buscado incansavelmente produtos alternativos, que sejam mais eficientes, baratos e ambientalmente seguros. Dentre as alternativas buscadas, o uso de extratos de plantas tem se mostrado promissor. Nesse sentido, o presente trabalho teve como objetivo testar 48 extratos aquosos e alcoólicos de 18 variedades de pimentas do gênero Capsicum obtidos a partir de sementes, folhas e frutos pelo método de maceração para o controle na inibição de germinação de Hemileia vastatrix e crescimento micelial dos fungos Colletotrichum lindemuthianum, Alternaria sp., Fusarium sp. Colletotrichum gloeosporioides e Phomopsis. Destes, o extrato aquoso, obtido de sementes de Capsicum chinense foi o mais eficiente, controlando todos os fitopatógenos desafiantes, mostrando que esses extratos possuem compostos bioativos possíveis de controlar fungos fitopatogênicos.
\end{abstract}

PALAVRAS-CHAVE: Doenças fúngicas, Inibição, Método alternativo.

\section{EXTRACTS OF CAPSICUM SPECIES IN THE IN VITRO CONTROL OF AGRICULTURAL IMPORTANCE PATHOGENS}

\begin{abstract}
Over the last 30 years, there has been a growing concern about the use of agrochemicals in agriculture. In this sense, the researchers has been relentlessly pursuing alternative products that are more efficient, cheap and environmentally safe. Among the alternatives sought, the use of plant extracts has shown promise. In this sense, the present work had the objective of testing 48 aqueous and alcoholic extracts of 18 varieties of Capsicum peppers obtained from seeds, leaves and fruits by the maceration method to control the inhibition of Hemileia vastatrix germination and mycelial growth of Fungi Colletotrichum lindemuthianum, Alternaria solani, Fusarium solani, Colletotrichum gloeosporioides and Phomopsis sp. From these, the aqueous extract obtained from Capsicum chinense seeds was the most efficient, controlling all the challenging phytopathogens
\end{abstract}

KEYWORDS: Fungal diseases, Inhibition, Alternative method. 


\section{INTRODUÇÃO}

Desde que o homem deixou de ser nômade e passou a cultivar o solo, as doenças de plantas acompanham seu progresso. Diversos grupos de microrganismos são causadores de doenças de plantas. Entre eles os fungos se destacam representando mais de $60 \%$ das doenças de plantas conhecidas (KIMATI et al., 1997; AGRIOS 2005).

A utilização de extratos surge como alternativa de controle para tais doenças, por utilizar material vegetal disponível, obtenção de extratos de maneira relativamente simples, sendo possível a utilização e obtenção de forma caseira. Dentre as espécies de plantas que apresentam potencial para uso como agentes de controle, as plantas gênero Capsicum apresentam enorme potencial antimicrobiano pela presença de princípios ativos com ação antioxidante contribuindo para a conservação de alimentos. Plantas condimentares, tais como as pimentas e pimentões são fontes naturais de vitamina $E$, vitamina $C$ e carotenoides (REIFSCHNEIDER, 2000).

É considerável a diversidade de substâncias que existem nas plantas e a possibilidade de se encontrar novas substâncias antifúngicas e inseticidas as quais poderiam ser utilizadas diretamente pelo produtor, por meio do cultivo da planta "fungicida", podendo o mesmo preparar e aplicar diretamente o extrato na planta cultivada. Outra possibilidade é a identificação de substância(s) nos extratos vegetais, com características fungicidas e inseticidas, as quais serviriam de modelo para a síntese de novos produtos futuramente (MAIA et al., 2015; FREIRE, 2016).

O Brasil é considerado centro da diversidade de pimentas Capsicum, pois em seu território podemos encontrar espécies de todos os níveis de domesticação (MARTINS et al., 2010; POZZOBON et al., 2011). O gênero Capsicum é composto por mais de 30 espécies, sendo cinco domesticadas e as demais classificadas como semidomesticadas e silvestres (MARTINS et al., 2010; BARBOZA et al., 2011).

A busca por métodos que sejam mais eficientes apresentam baixo custo, rápida e de fácil execução, com garantia de reprodutibilidade dos efeitos em campo em diferentes regiões, tipos de solo e sistemas de manejo da cultura tomou-se uma das áreas mais promissoras na pesquisa em controle biológico (MEDEIROS \& MONTEIRO, 2015).

Dessa forma, o presente trabalho teve como objetivo testar o efeito de extratos aquosos e alcoólicos de 18 variedades comerciais de pimentas para o controle na inibição de germinação de Hemileia vastatrix e crescimento micelial dos fungos Colletotrichum lindemuthianum, Alternaria sp., Fusarium sp., Colletotrichum gloeosporioides e Phomopsis sp.

\section{MATERIAL E MÉTODOS}

A pesquisa foi desenvolvida no Laboratório de Fitopatologia da Embrapa Rondônia no período de novembro de 2010 a novembro de 2011. Para os ensaios, foram utilizadas 18 cultivares comerciais de pimenta (Capsicum spp.), pertencentes ao Banco de Germoplasma do Centro Nacional de Pesquisas em Hortaliças da Embrapa - CNPH. As cultivares testadas e partes da planta utilizada estão listados a abaixo:

Folha: pimenta de gaúcho (Capsicum spp.); mexicana roxa comprida (Capsicum spp.); chifre de gazela (C. chinense Jacq.); peito de moça (C. annuum L.); três quinas (Capsicum spp.); tororó (Capsicum spp.); bode vermelha (C. chinense Jacq.); bode amarela ( $C$. chinense Jacq.); mexicana roxa pequena (Capsicum spp.); acerola (C. chinense Jacq.); Fruto: pimenta de gaúcho (Capsicum spp.); mexicana roxa comprida (Capsicum spp.); dedo-de-moça (C. baccatum L.); ENCICLOPÉDIA BIOSFERA, Centro Científico Conhecer - Goiânia, v. 14 n.25; p. 674 2017 
pimenta amarela ( $C$. annuum L.). Semente: pimenta de gaúcho (Capsicum spp.); mexicana roxa comprida (Capsicum spp.); dedo-de-moça (C. baccatum L.); biquinho ( $C$. chinense Jacq.), peito de moça ( $C$. annuum L.); pimenta amarela ( $C$. annuum L.); pimenta-dos-desejos (C. annuum L.); síria (C. chinense Jacq.); jurema (C. annuum L.); pitanga amarela ( $C$. baccatum L.); carrapeta (Capsicum spp.).

As pimentas foram inicialmente cultivadas no Campo Experimental da Embrapa no município de Ouro Preto D'Oeste - Rondônia. Com a maturação dos frutos, estes foram coletados, junto com folhas e ramos, sendo estas divididas em três partes para a obtenção dos extratos: sementes, polpa do fruto sem sementes e folhas. As pimentas foram lavadas em água corrente em seguida sanitizadas em água contendo hipoclorito de sódio $(0,5 \%)$ por 20 minutos.

Para obtenção dos extratos, foram pesadas 10 gramas do material congelado em balança digital. Em seguida, estes foram macerados com nitrogênio líquido até que se formasse um pó homogêneo e fino este foi transferido a Erlenmeyer de 250 $\mathrm{mL}$ e foram adicionados $100 \mathrm{~mL}$ do extrator (água e álcool etílico $96 \%$ G.L). O extrato obtido foi conservado em Erlenmeyer tampado e mantido sob agitação em mesa agitadora Kline modelo Q225K a 100 RPM por 24 horas.

Após este período esta suspensão foi filtrada em papel de filtro $100 \%$ celulose e posteriormente em gaze, a fim de retirar as partículas sólidas. Os extratos brutos $(100 \mathrm{mg} / \mathrm{mL})$ foram transferidos para frascos de vidro esterilizados e mantidos em geladeira para maior conservação. Para cada $100 \mathrm{~mL}$ de extrato, adicionou-se $2 \mathrm{~mL}$ do antibiótico de amplo espectro Cloranfenicol (500ppm), visando impedir o crescimento de contaminantes bacterianos. Os extratos foram utilizados para ensaios in vitro.

\section{ENSAIOS DE ANTIBIOGRAMA COM EXTRATOS BRUTOS $(100 \mathrm{mg} / \mathrm{mL})$}

Para realizar o antibiograma utilizou-se meio de cultura BCA (Batata-CenouraÁgar), que foi vertido na placa de Petri de $9 \mathrm{~cm}$ de diâmetro. Após a solidificação do meio foi adicionado no centro da placa um disco de micélio de $1 \mathrm{~cm}$ de diâmetro do fungo a ser testado: Colletotrichum lindemuthianum, Alternaria sp., Fusarium sp. Colletotrichum gloeosporioides e Phomopsis sp..

Ao redor do disco, de forma equidistante, perfurações foram feitas com furador de tecidos vegetais de $0,5 \mathrm{~cm}$ de diâmetro por $1 \mathrm{~cm}$ de profundidade, num total de cinco por placa. Dentro destas cavidades, foram dispensados $20 \mu \mathrm{l}$ dos extratos com auxilio de pipeta automática. Em cada placa foram testados cinco tipos de extratos. Paralelamente preparou se placas contendo as testemunhas etanol a 96ํㅡ $\mathrm{GL}$, água e o fungicida comercial Benomil $(0,6 \mathrm{~g} / \mathrm{l})$. As placas foram mantidas em incubadora tipo B.O.D. em temperatura média de $25^{\circ} \mathrm{C}\left( \pm 1^{\circ} \mathrm{C}\right)$ por 72 horas, num regime de foto período de 12 horas claro/escuro. O acompanhamento do crescimento do fungo foi diário e mediu-se o diâmetro médio dos halos de inibição, quando ocorreram, com paquímetro digital (ROMEIRO, 2007).

Os extratos que apresentaram resultados de inibição de crescimento micelial nos ensaios primários, em que se utilizou extratos brutos $(100 \mathrm{mg} / \mathrm{mL})$, foram então diluídos em base $10(10 \mathrm{mg} / \mathrm{mL}, 1 \mathrm{mg} / \mathrm{mL}$ e $0,1 \mathrm{mg} / \mathrm{mL})$ e, em seguida, testados em ensaios similares nessas diferentes concentrações, a fim de se determinar até que dose os extratos apresentariam seu efeito inibitório.

\section{AVALIAÇÃO DE GERMINAÇÃO DOS UREDÓSPOROS DE HEMILEIA VASTATRIX}

Para avaliar o efeito dos extratos alcoólicos e aquosos de pimenta sobre a germinação de uredósporos, os últimos foram coletados de folhas de cafeeiro 
contaminadas, pelo método de raspagem com pincel. A suspensão de esporos foi preparada transferindo-se uma porção do mesmo para Becker contendo $50 \mathrm{~mL}$ de água e adicionada 1 gota de tween $20 \%$. Esta foi agitada com bastão de vidro. Foram incorporados $10 \mathrm{~mL}$ do extrato ao meio Ágar-Água semissólido $(90 \mathrm{~mL})$ e este foi vertido em placas de Petri de $9 \mathrm{~cm}$ de diâmetro. A suspensão de esporos foi depositada sobre o meio e espalhada com alça de Drigalski. Como controle, placas contendo o meio sem a adição de extratos. Após 12 horas a 25 $\mathrm{C}$ no escuro em câmera tipo B.O.D, avaliou-se a porcentagem de germinação dos mesmos.

O delineamento experimental utilizado nos ensaios foi do tipo inteiramente casualizado (DIC) com 48 tratamentos (pimentas: parte da planta: tipo de extrator: diluição) em quatro repetições para cada tratamento testado, sendo a unidade amostral composta por uma placa de Petri. Os dados obtidos foram submetidos à análise de variância e as médias dos tratamentos foram agrupadas, por meio deteste de comparação de médias Tukey a $5 \%$ de probabilidade.

\section{RESULTADOS E DISCUSSÃO}

Das 18 variedades de pimentas selecionadas para os ensaios in vitro, foram obtidos 48 extratos, sendo 25 extratos alcoólicos e 23 extratos aquosos. Em se tratando do efeito de inibição micelial dos extratos contra os patógenos Colletotrichum lindemuthianum, Alternaria, Fusarium oxysporum, Phomopsis e Colletotrichum gloeosporioides, dos 48 extratos testados, apenas aqueles obtidos a partir de extração à base de água e macerados de sementes de: Pimenta Dedo-deMoça ( $C$. baccatum L.), Biquinho ( $C$. chinense Jacq.), Síria ( $C$. chinense Jacq.), Jurema (C. annuum L.), Pitanga Amarela (C. baccatum L.), Dos Desejos (C. annuum L.), Gaúcho (Capsicum spp.), Amarela (C. annuum L.), Peito-de-Moça (C. annuum L.), Carrapeta (Capsicum spp.), Mexicana Roxa Comprida (Capsicum spp.), frutos de: Pimenta Dedo-de-Moça (C. baccatum L.), Amarela (C. annuum L.), Gaúcho (Capsicum spp.), Mexicana Roxa Comprida (Capsicum spp.) e folhas de: Pimenta Bode Amarela (C. chinense Jacq.), Tororó (Capsicum spp.), Três Quinas (Capsicum spp.), Chifre de Gazela ( $C$. chinense Jacq.), Acerola (C. chinense Jacq.), Mexicana Roxa Comprida (Capsicum spp.), Bode Vermelha (C. chinense Jacq.), Gaúcho (Capsicum spp.) e Peito-de-Moça (C. annuum L.) apresentaram inibição do crescimento micelial.

Extratos testados obtidos a partir de álcool e macerados de semente de pimentas Peito-de-Moça (C. annuum L.), Mexicana Roxa comprida (Capsicum spp.), Biquinho (C. chinense Jacq.), Dedo-de-Moça (C. baccatum L.), Dos Desejos (C. annuum L.), Pitanga Amarela ( $C$. baccatum L.) e Mexicana Roxa Pequena (Capsicum spp.) e folha de pimenta de Gaúcho (Capsicum spp.) apresentaram inibição significativa do patógeno Colletotrichum lindemuthianum, quando comparados ao tratamento controle com água, embora tenham sido menos eficientes que o fungicida usado como controle positivo (Figura 1). 


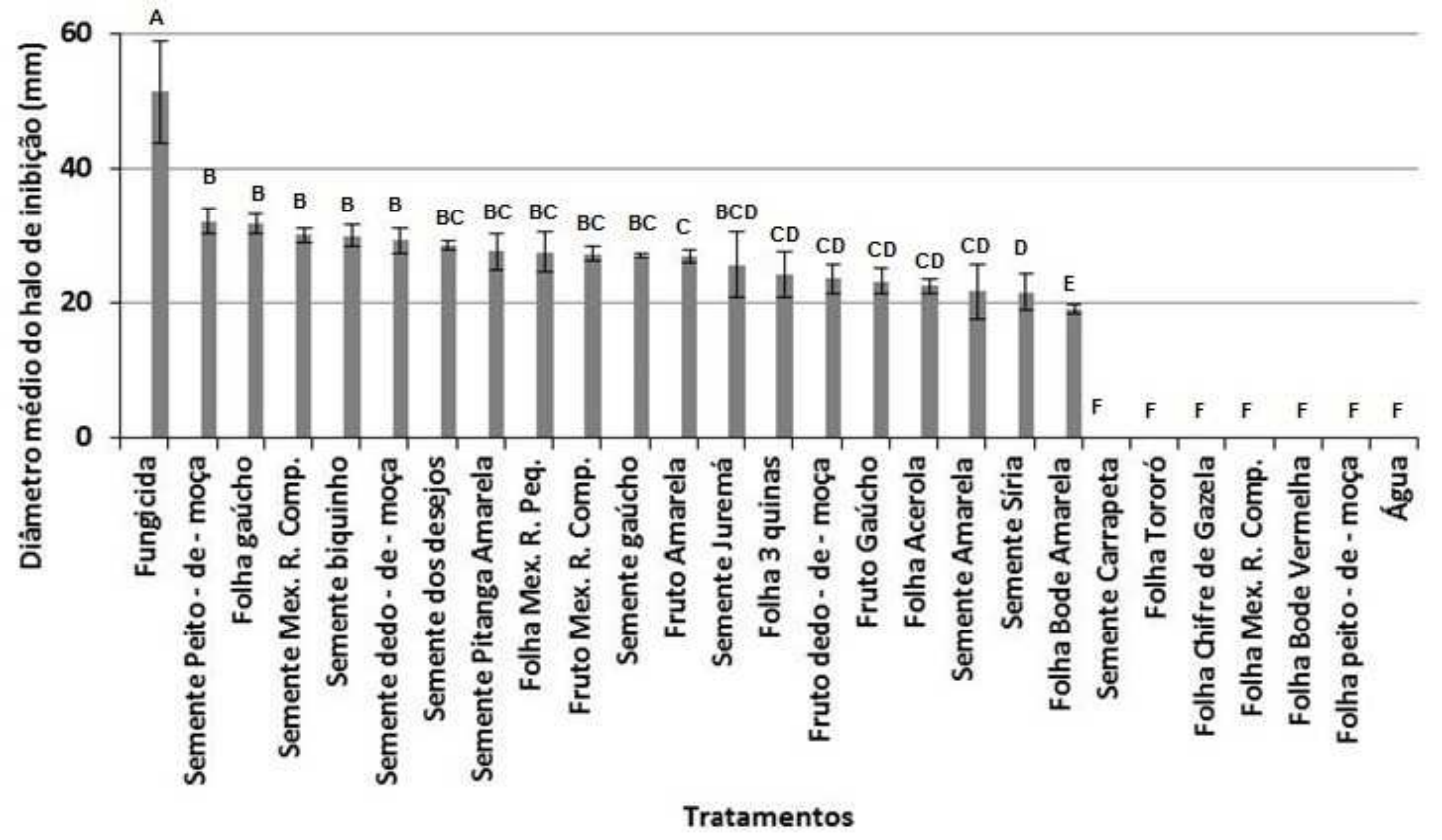

FIGURA 1 - Diâmetro médio do halo de inibição do crescimento micelial de Colletotrichum lindemuthianum quando exposto a extratos aquosos de pimentas. Médias seguidas da mesma letra não diferem entre si pelo teste de Tukey ao nível de $5 \%$ de probabilidade. As barras indicam o desvio padrão da média.

Contra Fusarium oxysporum destacaram-se as sementes de pimenta Peitode-Moça (C. annuum L.), Dedo-de-Moça (C. baccatum L.), Dos Desejos (C. annuum L.), e Gaúcho (Capsicum spp.), folhas de pimenta Chifre de Gazela (C. chinense Jacq.), e Mexicana Roxa Comprida (Capsicum spp.), com resultados significante de redução total $70 \%$ comparado com o controle com água (Figura 2). 


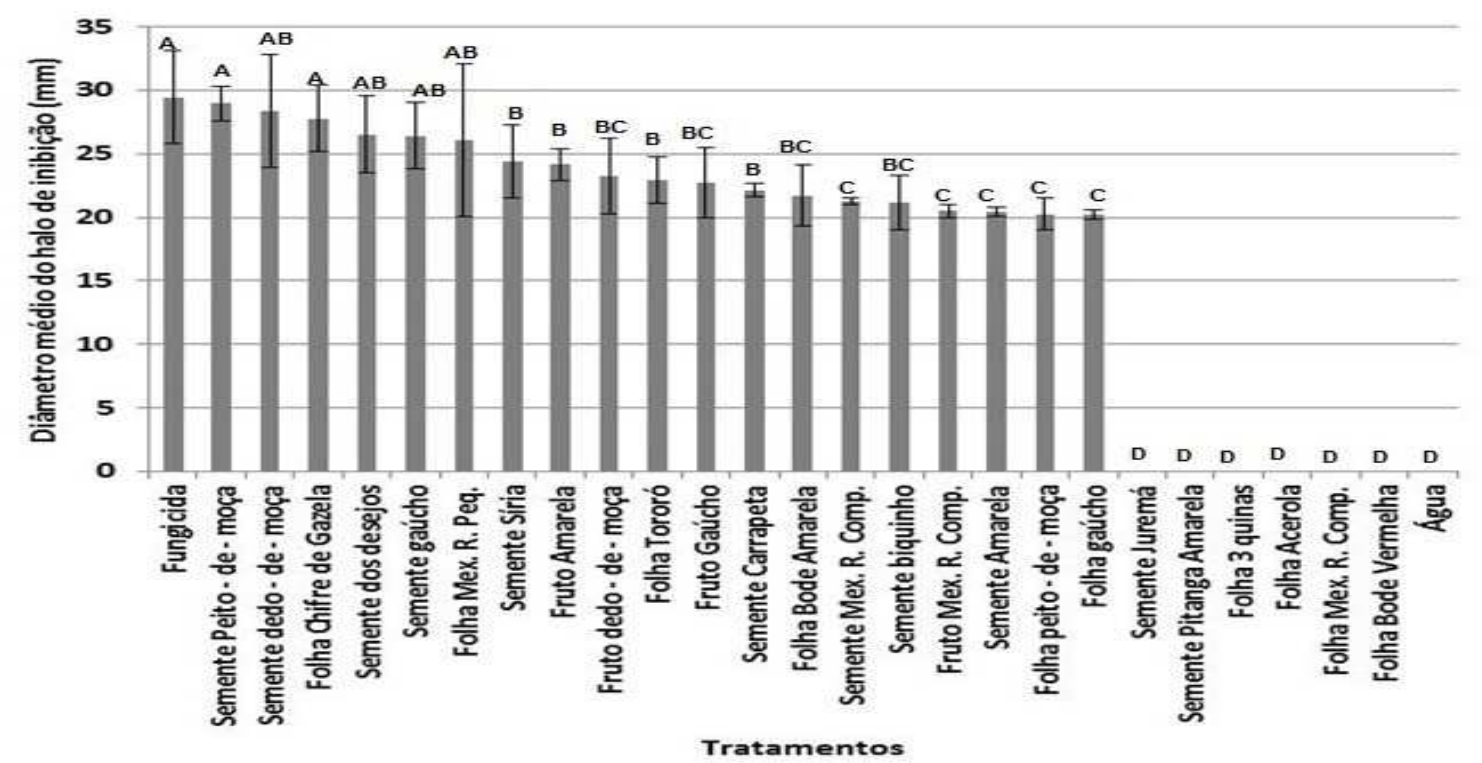

FIGURA 2. Diâmetro médio do halo de inibição do crescimento micelial de Fusarium oxysporum quando exposto a extratos aquosos de pimentas. Médias seguidas de mesma letra não diferem entre si pelo teste de Tukey ao nível de $5 \%$ de probabilidade. As barras indicam o desvio padrão da média.

Contra Alternaria sp. Destacaram-se as folhas de pimenta Acerola ( $C$. chinense Jacq.), Mexicana Roxa Comprida (Capsicum spp.), Mexicana Roxa pequena (Capsicum spp.) e semente de pimenta dos Desejos (C. annuum L.) com resultados significantes de redução total $77 \%$ comparado com o controle com água (Figura 3).

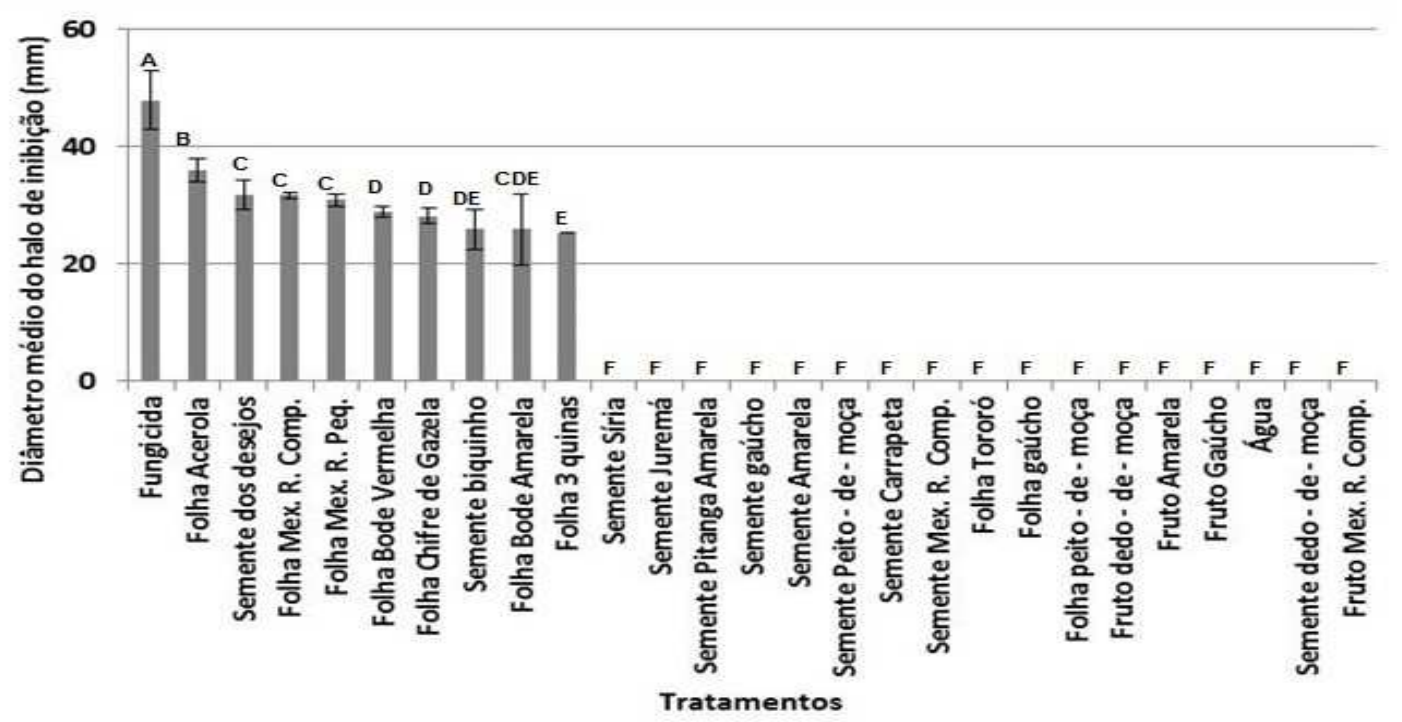

FIGURA 3. Diâmetro médio do halo de inibição do crescimento micelial de Alternaria $s p$. quando exposto a extratos aquosos de pimentas. Médias seguidas de mesma letra não diferem entre si pelo teste de Tukey ao nível de $5 \%$ de probabilidade. As barras indicam o desvio padrão da média. 
Contra o fungo Phomopsis sp. Destaca-se o obtido de folhas de pimenta Tororó (Capsicum spp.), Acerola (C. chinense Jacq.), Chifre de Gazela (C. chinense Jacq.), Três Quinas (Capsicum spp.) e Bode Vermelha (C. chinense Jacq.) e sementes de pimenta Biquinho (C. chinense Jacq.), Mexicana Roxa Comprida (Capsicum spp.), e Carrapeta (Capsicum spp.) com $70 \%$ de redução de crescimento micelial quando comparado com o controle fungicida (Figura 4).

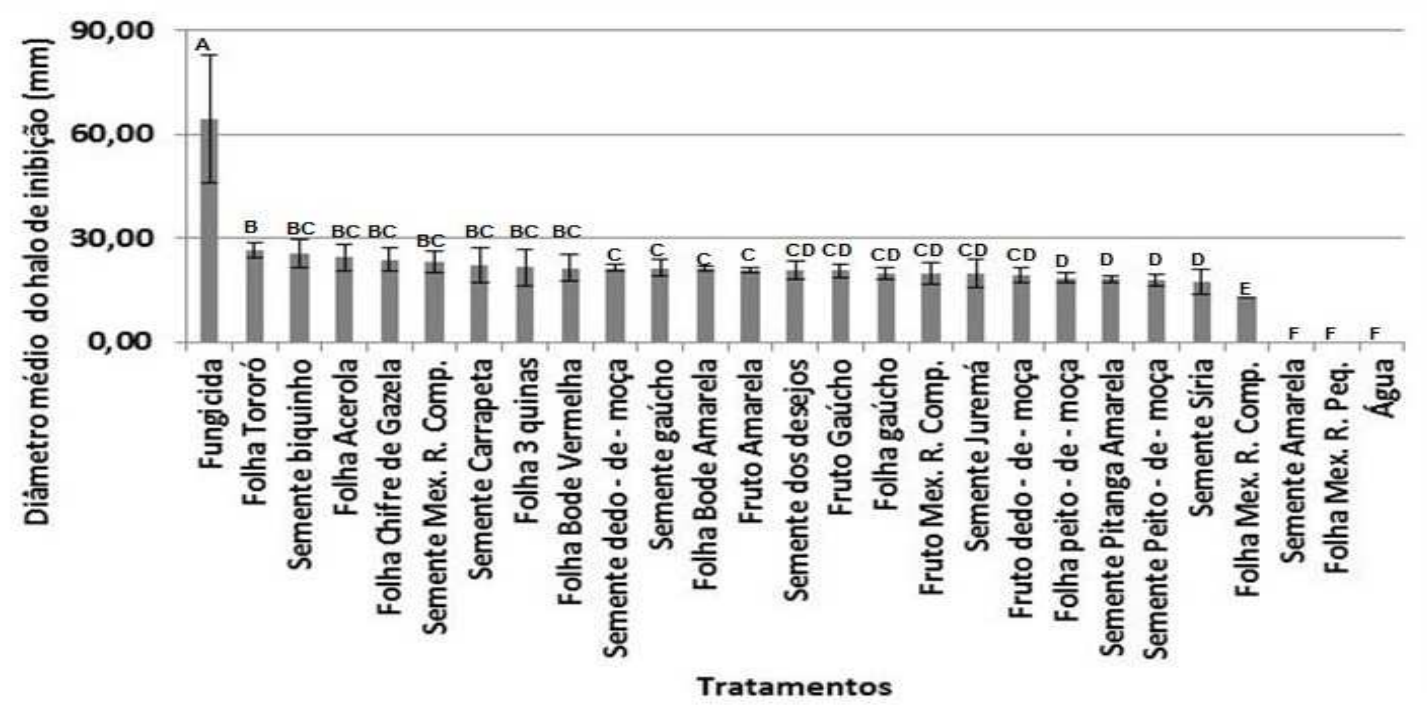

FIGURA 4 - Diâmetro médio do halo de inibição do crescimento micelial de Phomopsis quando exposto a extratos aquosos de pimentas. Médias seguidas de mesma letra não diferem entre si pelo teste de Tukey ao nível de $5 \%$ de probabilidade. As barras indicam o desvio padrão da média.

Contra o crescimento micelial do fungo C. gloeosporioides dentre todos os extratos testados destacam-se os obtidos de folhas de pimenta Tororó (Capsicum spp.), Gaúcho (Capsicum spp.) e Mexicana Roxa pequena (Capsicum spp.), com $80 \%$ de redução de crescimento micelial, quando comparado com o controle com fungicida (Figura 5). 


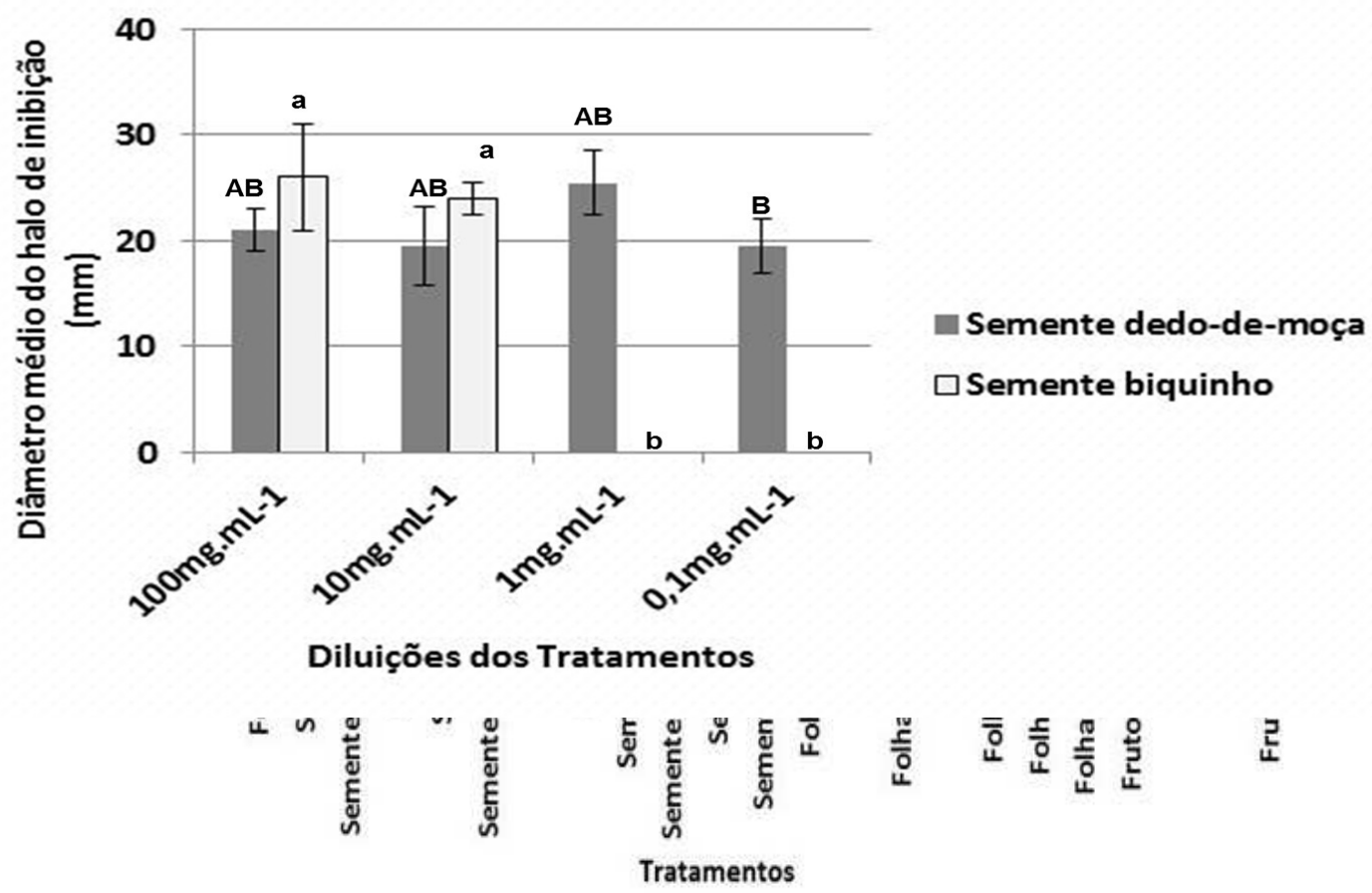

FIGURA 5. Diâmetro médio do halo de inibição do crescimento micelial de $C$. gloeosporioides quando exposto a extratos aquosos de pimentas. Médias seguidas de mesma letra não diferem entre si pelo teste de Tukey ao nível de $5 \%$ de probabilidade. As barras indicam o desvio padrão da média.

Para C. lindemuthianum dos 48 extratos testados, apenas os oriundos de sementes de 'Biquinho (C. chinense Jacq.)' e 'Dedo-de-moça (C. baccatum L.)' apresentaram efeito inibitório contra o patógeno. Os extratos de pimenta biquinho (C. chinense Jacq.) apresentaram efeito inibitório quando diluídos até a diluição de $10 \mathrm{mg} / \mathrm{mL}$. Já os extratos aquosos de pimenta dedo-de-moça (C. baccatum L.) foram capazes de inibir o crescimento do fungo até a diluição de $0,1 \mathrm{mg} / \mathrm{mL}$.

Não houve diferença significativa entre os tratamentos, quando o extrato foi diluído até 1000 vezes da concentração original. Este efeito de redução de eficiência de controle só foi significativo em diluição a $0,1 \mathrm{mg} / \mathrm{mL}$, embora não tenha sido proporcional o efeito de redução de inibição (Figura 6). 


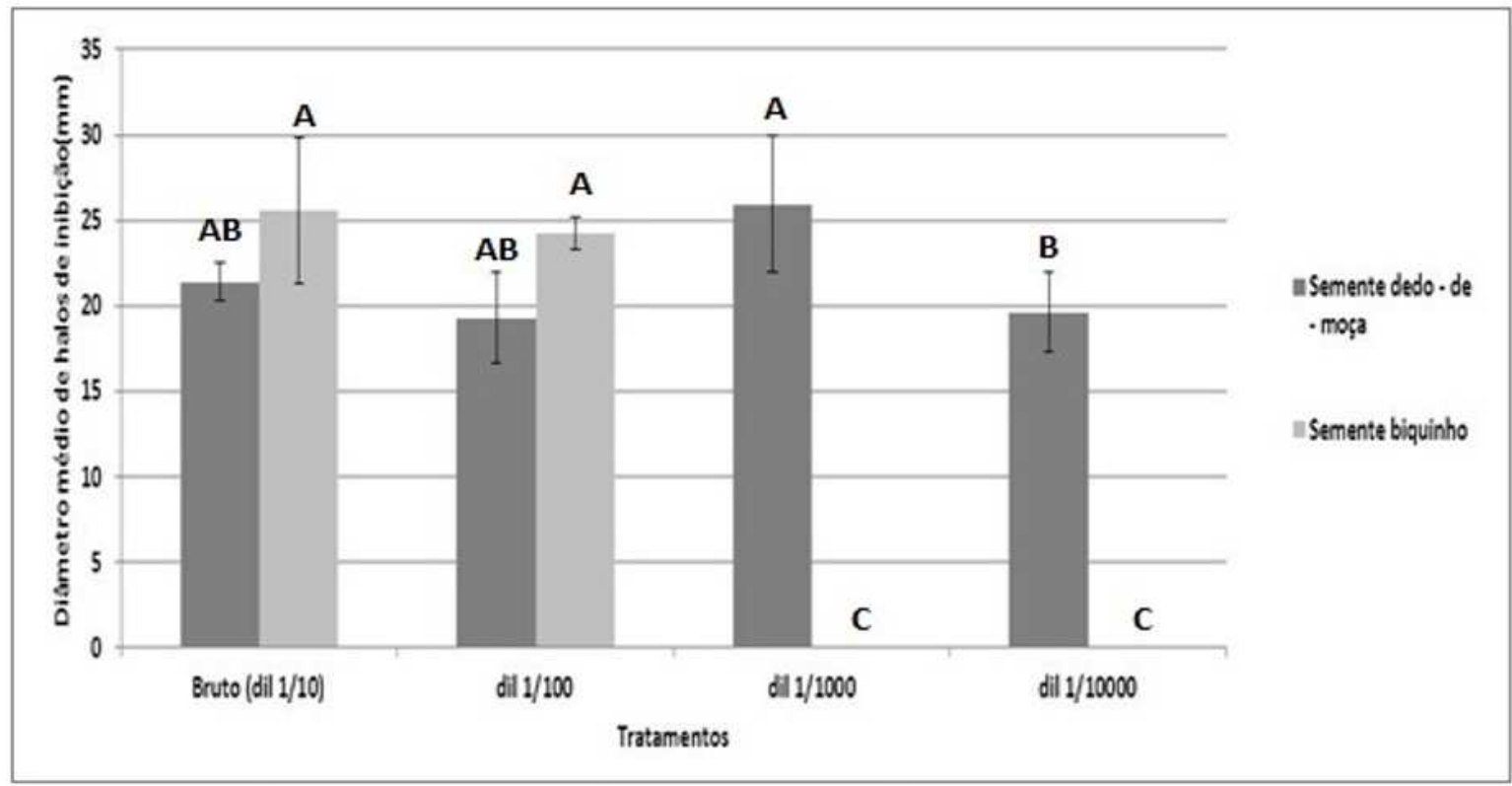

FIGURA 6. Diâmetro médio do halo de inibição do crescimento micelial de Colletotrichum lindemuthianum quando exposto a extratos aquosos de sementes das pimentas 'dedo-de-moça (C. baccatum L.)' e 'biquinho (C. chinense Jacq.)' em diferentes diluições. Médias seguidas de mesma letra não diferem entre si pelo teste de Tukey ao nível de $5 \%$ de probabilidade. As barras indicam o desvio padrão da média.

$\mathrm{Na}$ literatura atual é possível encontrar alguns trabalhos que demonstram a potencialidade de extratos de plantas do gênero Capsicum (GUIMARÃES, et al., 2013; CORRÊA, 2015; VIEIRA JUNIOR et al., 2016). CORRÊA (2015) testando extratos dos frutos e folhas de Capsicum frutescens e $C$. baccatum sobre o fungo $C$. gloeosporioides demonstrou que os mesmos apresentaram propriedades fungitóxicas inibindo o crescimento micelial em 32,16 e 27,37\% comparados com o controle. VIEIRA JUNIOR e colaboradores (2016) trabalhando com diferentes extratos de pimenta (Capsicum sp.) sobre o crescimento micelial de Rhizoctonia solani observaram que, nos ensaios de diluição 1:1000 e 1:10.000, todos apresentaram halo de inibição contra o fungo testado sendo mais eficaz na maior concentração.

Isso também foi observado por BERNARDO et al., (2015), para a variável inibição do crescimento micelial, o extrato de carqueja promoveu as maiores inibições em A. alternata, C. graminicola, Phytophthora sp. e R. solani, enquanto que para $S$. rolfsii o melhor extrato foi de manjericão. Observou-se que a maioria dos extratos aquosos apresentou comportamento dose dependente isto é, com o aumento da concentração de cada extrato, maior foi a inibição do crescimento dos fitopatógenos. 
Neste contexto ZACARONI et al. (2009) trabalhando com o óleo essencial de pimenta longa na concentração de $200 \mu \mathrm{g} \cdot \mathrm{mL}^{-1}$ observaram que o óleo inibiu totalmente o crescimento do fitopatógeno Bipolaris sorokiniana enquanto que, para o Fusarium oxysporume o Colletotrichum gloeosporioides esta ocorreu na concentração de $1000 \mu \mathrm{g} \cdot \mathrm{mL}^{-1}$. De forma similar ao trabalho citado anteriormente, possível observar que, dos extratos obtidos das 18 variedades avaliadas neste ensaio, extratos obtidos a partir da maceração de sementes apresentaram efeitos significativos para todos os patógenos testados, levando-se a julgar que, compostos com ação antifúngica possivelmente estejam concentrados neste órgão. Além disso,

Dos extratos aquosos obtidos à base de folhas, aqueles obtidos de pimentade-gaúcho (Capsicum spp.), bode amarela (C. chinense Jacq.) e mexicana-roxapequena (Capsicum spp.) apresentaram os melhores resultados, inibindo cinco dos seis fungos testados, sendo que a primeira não inibiu $C$. lindemuthianum, a segunda não inibiu Alternaria sp. e a última não inibiu Phomopsis sp.

Dos 48 extratos obtidos e testados neste trabalho, apenas aqueles obtidos a partir de extração à base de água/álcool e macerados de sementes de: Pimenta 'Dedo-de-Moça (C. baccatum L.), 'Biquinho (C. chinense Jacq.)', 'Síria (C. chinense Jacq.)', 'Jurema (C. annuum L.)', 'Pitanga Amarela (C. baccatum L.)', 'Dos Desejos (C. annuum L.)', 'Gaúcho (Capsicum spp.)', 'Amarela (C. annuum L.)', 'Peito-deMoça (C. annuum L.)', 'Carrapeta (Capsicum spp.)', 'Mexicana Roxa Comprida (Capsicum spp.)', frutos de: Pimenta 'Dedo-de-Moça (C. baccatum L.)', 'Amarela (C. annuum L.)', 'Gaúcho (Capsicum spp.)', 'Mexicana Roxa Comprida (Capsicum spp.)' e folhas de: Pimenta 'Bode Amarela', 'Tororó (Capsicum spp.)', 'Três Quinas (Capsicum spp.)', 'Chifre de Gazela (C. chinense Jacq.)', 'Acerola (C. chinense Jacq.)', 'Mexicana Roxa Comprida (Capsicum spp.)', 'Bode Vermelha (C. chinense Jacq.)', 'Gaúcho (Capsicum spp.)' e 'Peito-de-Moça (C. annuum L.)' promoveram a redução na germinação de Uredósporos de Hemileia vastatrix, com inibição variando entre 70 a $100 \%$ de inibição da germinação dos esporos (Figura 07). Destes, os obtidos de folhas de pimenta 'Bode Amarela ( $C$. chinense Jacq.)', folhas de pimenta 'de Gaúcho (Capsicum spp.)', folhas pimenta 'Peito-de-Moça (C. annuum L.)' e Semente pimenta 'Juremá (C. annuum L.)' apresentaram eficiência de controle semelhante ao fungicida comercial Oxicloreto de Cobre (Figura 7). 


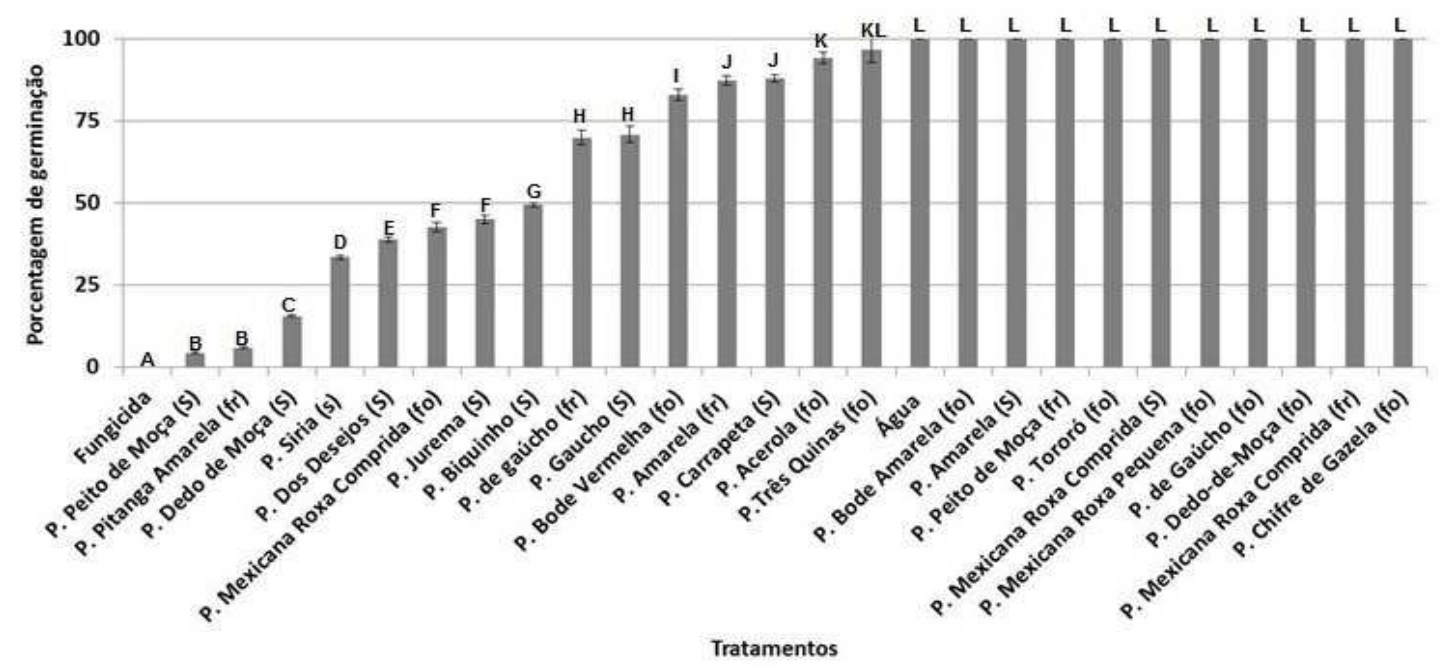

FIGURA 7. Média da porcentagem de germinação de uredósporos de $H$. vastatrix expostos a extratos aquosos obtidos de folhas, frutos $\mathrm{e}$ sementes de pimentas do gênero Capsicum. Médias seguidas da mesma letra não diferem entre si, pelo teste de Tukey a $5 \%$. As barras indicam o desvio padrão. Legenda: (Fo) - Folha; (S) semente; (fr) - fruto.

Por fim, duas questões devem ser consideradas. A primeira diz respeito ao tipo de extrato que apresentou resultados de controle. Neste trabalho, observou-se que os extratos aquosos apresentaram eficiência elevada, quando comprados aos extratos obtidos a partir da extração alcoólica. À exceção do efeito dos extratos alcoólicos contra a germinação de esporos de $H$. vastatrix nenhum dos extratos alcoólicos apresentou controle sobre os demais fungos em crescimento micelial. Este fator tem dois aspectos positivos. $\mathrm{O}$ primeiro diz respeito à possibilidade $\mathrm{e}$ restrições de uso de extratos alcoólicos, uma vez que este extrator pode provocar fito toxicidade às plantas-alvo e mesmo, pode auxiliar na degradação de ceras protetoras das folhas tornando a planta mais suscetível ao ataque de patógenos. $O$ segundo aspecto diz respeito ao uso pelo agricultor. É fato de que extratos aquosos são menos perigosos de preparar e manusear e, por serem, obviamente, feitos à base de água, são mais baratos e fáceis de serem obtidos.

A segunda questão, diz respeito à capacidade de controle dos extratos quando diluídos. Os ensaios anteriores mostraram que a diluição dos extratos pode provocar a inativação dos mesmos, tornando-os ineficazes ou, como no caso de pimenta 'dedo-de-moça ( $C$. baccatum L.)', mesmo em diluições mais elevadas a resposta de controle continua inalterada. Assim mais testes precisam ser feitos para determinar o limite máximo de diluição de cada extrato, antes da recomendação para uso em campo.

Destes 48 extratos testados, aqueles obtidos a partir de extração à base de água e álcool de sementes de: Pimenta Dedo-de-Moça ( $C$. baccatum L.), Biquinho (C. chinense Jacq.), Síria (C. chinense Jacq.), Jurema ( $C$. annuum L.), Pitanga Amarela (C. baccatum L.), Dos Desejos (C. annuum L.), 'Gaúcho (Capsicum spp.)', 'Amarela (C. annuum L.)', 'Peito-de-Moça (C. annuum L.)', 'Carrapeta (Capsicum spp.)', 'Mexicana Roxa Comprida (Capsicum spp.)', frutos de: Pimenta 'Dedo-deMoça (C. baccatum L.)', 'Amarela (C. annuum L.)', 'Gaúcho (Capsicum spp.)', 
'Mexicana Roxa Comprida (Capsicum spp.)' e folhas de: Pimenta 'Bode Amarela (C. chinense Jacq.)', 'Tororó (Capsicum spp.)', 'Três Quinas (Capsicum spp.)', 'Chifre de Gazela (C. chinense Jacq.)', 'Acerola (C. chinense Jacq.)', 'Mexicana Roxa Comprida (Capsicum spp.)', 'Bode Vermelha (C. chinense Jacq.)', 'Gaúcho (Capsicum spp.)' e 'Peito-de-Moça (C. annuum L.)' promoveram a redução na germinação de Uredósporos de Hemileia vastatrix.

Destes, os obtidos de folhas de pimenta Bode Amarela (C. chinense Jacq.), pimenta de Gaúcho (Capsicum spp.), Peito-de-Moça (C. annuum L.) e Semente de pimenta Juremá apresentaram eficiência de controle semelhante ao fungicida comercial Oxicloreto de Cobre. De todos os extratos testados, apenas aqueles obtidos de sementes da variedade Biquinho foram capazes de inibir todos os patógenos testados e, mesmo assim se considerarmos que no caso de $H$. vastatrix o extrato que apresentou efeito de controle foi o alcoólico e não o aquoso.

Dos resultados dos ensaios descritos anteriormente é possível inferir que o uso de extratos de planta, mais especificamente o de pimentas do gênero Capsicum, no controle de doenças de plantas não é apenas uma questão potencial, pois os mesmos extratos e óleos essenciais extraídos de plantas possuem substâncias que se acumulam nas plantas com grande potencial no controle de fitopatógenos, por sua ação fungitóxica direta, inibindo o crescimento micelial e a germinação de esporos (BIGATON, 2013).

Nestes ensaios, uma variedade de gêneros de fitopatógenos distintos foi testada e se obteve sucesso na inibição do crescimento dos mesmos e, em alguns casos, com níveis de inibição semelhantes ao controle químico comercial, como foi o caso de bode amarela (C. chinense Jacq.), 'Pitanga amarela ( $C$. baccatum L.)' e 'peito-de-moça (C. annuum L.)' contra $H$. vastatrix, das pimentas de gaúcho (Capsicum spp.), tororó (Capsicum spp.) e mexicana-roxa-pequena (Capsicum spp.) contra $C$. lindemuthianum e dos extratos das pimentas chifre-de-gazela $(C$. chinense Jacq.), dedo-de-moça ( $C$. baccatum L.) e peito-de-moça ( $C$. annuum L.) contra Fusarium oxysporum.

\section{CONCLUSÃO}

Todos os extratos testados apresentaram algum nível de inibição contra os fitopatógenos desafiados.

A extração de base aquosa mostrou-se mais eficiente que aquela feita com o uso de álcool etílico, demonstrando que provavelmente, compostos fungitóxico presentes nos tecidos têm origem polar.

A extração de compostos da pimenta 'biquinho (C. chinense Jacq.)', deve ser melhor explorado, haja visto a amplitude de controle observada, tanto para fungos necrotrófico (Colletotrichum sp., Alternaria sp. e Fusarium sp.) quanto para fungos biotróficos.

\section{REFERÊNCIAS}

AGRIOS, G. N. Plant pathology. 5. ed. Amsterdam: Elsevier: Academic Press, 2005. $922 \mathrm{p}$. 
BARBOZA, G. E.; AGRA, M. F.; ROMERO, M. V.; SCALDAFERRO, M. A.; MOSCONE, E. A. New Endemic Species of Capsicum (Solanaceae) from the Brazilian Caatinga: Comparison with the Re-circumscribed $C$. parvifolium. Systematic Botany, v. 36, n. 3, p. 768-781, 2011. Disponível em: <https://doi.org/10.1600/036364411x583718>. doi: 10.1600/036364411X583718

BERNARDO, R.; SCHWAN-ESTRADA, K. R. F.; STANGARLIN, J. R.; OLIVEIRA, J. S. B.; CRUZ, M. E. S.; MESQUINI, R. M. Atividade fungitóxica in vitro de extratos vegetais sobre o crescimento micelial de fungos fitopatogênicos. Scientia Agraria Paranaensis. v. $14, \quad$ n. 2, p. 89-93, 2015. Disponível em: <http://dx.doi.org/10.18188/1983-1471/sap.v14n2p89-93>. doi: $10.18188 / 1983-$ 1471/sap.v14n2p89-93

BIGATON, D.; BACCHI, L. M. A.; FORMAGIO, A. S. N. F.; GAVASSONI, W. L.; ZANELLA, C. S. Avaliação da atividade fungicida de extratos e óleos essenciais sobre ferrugem asiática da soja. Revista Ciência Agronômica. v. 44, n. 4, 2013. Disponível em: <http://dx.doi.org/10.1590/S1806-66902013000400012>. doi: 10.1590/S1806-66902013000400012

CORRÊA, J. A. M. Estudo químico de extrato de plantas da família solanaceae com atividade a fungos fitopatogênicos. 2015. 164p. Tese (Doutorado em ciências)., Universidade de São Paulo, Piracicaba, 2015.

FERRAZ, R. M. Caracterização preliminar morfológica e agronômica de pimentas cumari (Capsicum baccatum L. var. praetermissum e Capsicum baccatum L. var. baccatum). 2012. 62f. Trabalho de Conclusão de Curso (Monografia) - Universidade de Brasília, Brasília, 2012.

FREIRE, G. F.; LEITE, D. T.; PEREIRA R. A.; MELO, B. A.; SILVA, J. F.; MARACAJÁ, P. B.; Bioatividade de Solanum melongena L. E Capsicum annuum L. sobre Callosobruchus maculatus (COLEOPTERA: BRUCHIDAE). Acta biológica Colombiana. v. 21, n. 1, 2016. Disponível em: <http://dx.doi.org/10.15446/abc.v21n1.45775>. doi: 10.15446/abc.v21n1.45775

GUIMARÃES, S. S.; POTRICH, M.; SILVA, E. R. L.; WOLF, J.; PEGORINI, C. S.; OLIVEIRA, T. M. Ação repelente, inseticida e fagoinibidora de extratos de pimenta dedo-de-moça sobre o gorgulho do milho. Arquivos do Instituto Biológico. v. 81, n. 4, p. 322-328, 2014. Disponível em: <http://www.scielo.br/pdf/aib/v81n4/0020-3653-aib-81-04-0322.pdf>. 10.1590/1808-1657000172013

KIMATI, H.; AMORIM, L.; BERGAMIN FILHO, A.; CAMARGO, L.E. A.; REZENDE, J.A.M. (Ed.). Manual de fitopatologia: doenças das plantas cultivadas. 3. ed. São Paulo : Agronômica Ceres, 1997. v. 2, 774p.

MAIA, T. F.; DONATO, A.; FRAGA, M. E. Atividade antifúngica de óleos essenciais de plantas. Revista Brasileira de Produtos Agroindustriais, v. 17, n. 1, p.105-116, 2015. Disponível em: <https://doi.org/10.15871/1517-8595/rbpa.v17n1p105-116>. doi: 10.15871/1517-8595/rbpa.v17n1p105-116 
MARTINS, K. C.; PEREIRA, T. N. S.; SOUZA S. A. M.; COSTA, F. R. Meiose e viabilidade polínica em acessos de Capsicum annuum e Capsicum baccatum. Ciência Rural, v. 40, n. 8, 2010. Disponível em: <https://doi.org/10.1590/s010384782010000800012>. doi: 10.1590/S0103-84782010000800012

MEDEIROS F. H. V.; MONTEIRO F. P. Perspectivas do controle biológico de doenças de plantas no Brasil. Universidade Estadual do Oeste do Paraná, 2015. 360p. In: Ciências agrárias - Tecnologias e perspectivas. Disponível em: $<$ http://dx.doi.org/10.12702/978-85-68205-03-7.9>.

POZZOBON, M. T; SOUZA, K. R. R; CARVALHO, S. I. C; REIFSCHNEIDER, F. J. B. Meiose e viabilidade polínica em linhagens avançadas de pimenta. Horticultura Brasileira. v. 29, n. 2, 2011. Disponível em: <https://doi.org/10.1590/s010205362011000200013 > . doi: 10.1590/S0102-05362011000200013

PINTO, C. M. F.; PINTO, C. L. O.; DONZELES, S. M. L. Pimenta Capsicum: propriedades químicas, nutricionais, farmacológicas e medicinais e seu potencial para o agronegócio. Revista Brasileira de Agropecuária Sustentável, v. 3, n. 2, p. 108-120, 2013. Disponível em: <http://dx.doi.org/10.21206/rbas.v3i2.225>. doi: $10.21206 /$ rbas.v3i2.225

REIFSCHNEIDER, F. J. B. Capsicum Pimentas e Pimentões do Brasil. Brasília, DF: Embrapa Comunicação para transferência de tecnologia/Embrapa Hortaliças, 2000. P. 113.8

ROMEIRO, R. S. Controle biológico de doenças de plantas - Fundamentos. Viçosa, Editora UFV, 291p. 2007.

VIEIRA JUNIOR, J. R.; FERNANDES, C. F.; ALVES, R. C.; FONSECA, A. S.; FREIRE, T.C Extratos de pimentas (Capsicum spp.) para inibição do crescimento micelial in vitro de Rhizoctonia solani Kuhn. Enciclopédia Biosfera, Centro Científico Conhecer, v. 13, n. 23, 15 p, 2016. Disponível em: <https://doi.org/10.18677/enciclopedia_biosfera_2016_152 >. doi: 10.18677/Enciclopedia_Biosfera_2016_152

ZACARONI, L. M.; CARDOSO, M. G.; SOUZA, P. E.; PIMENTEL, F. A.; GUIMARÃES, L. G. L.; SALGADO, A. P. S. P. Potencial fungitóxico do óleo essencial de Piper hispidinervum (pimenta longa) sobre os fungos fitopatogênicos Bipolaris sorokiniana, Fusarium oxysporum e Colletotrichum gloeosporioides. Acta Amazônica. v. 39, n. 1, 2009. Disponível em: <https://doi.org/10.1590/s0044-59672009000100020 >. doi: 10.1590/S004459672009000100020 